The original publication is available at www.springerlink.com

http://dx.doi.org/10.1007/s10682-010-9391-4

Evolutionary Ecology (2011) 25:155-169

\title{
Are the best dispersers the best colonizers? Seed mass, dispersal and establishment in Carduus thistles
}

\author{
Olav Skarpaas ${ }^{1}$, Edward J. Silverman ${ }^{2}$, Eelke Jongejans ${ }^{3}$ \& Katriona Shea ${ }^{2}$
}

1. Corresponding author: Norwegian Institute for Nature Research, Gaustadalléen 21, NO0349 Oslo, Norway, olav.skarpaas@nina.no

2. The Pennsylvania State University, Department of Biology and IGDP in Ecology, 208 Mueller Laboratory, University Park, 16802 PA, USA

3. Radboud University Nijmegen, Institute for Water and Wetland Research, Department of Experimental Plant Ecology, Heyendaalseweg 135, 6525 AJ Nijmegen, The Netherlands

Running title: Seed mass, dispersal and establishment in Carduus

Key words: colonization; establishment; germination; seed mass; dispersal-establishment trade-off; wind dispersal

\section{Abstract}

The negative correlation between dispersal and establishment appears to be well documented in the plant literature; smaller seeds tend to disperse better but germinate less well, and produce smaller seedlings. However, because dispersal capacity is often quantified using proxies, such as the settling velocity of wind-dispersed seeds, little is known about the exact shape of this negative correlation, and how it is modified by other plant traits and environmental conditions. We studied the dispersal-establishment correlation in two winddispersed thistles (Carduus nutans and Carduus acanthoides). We applied a mechanistic wind dispersal model (WALD) to seeds released under a range of environmental conditions, and tested germination and seedling growth under standardized conditions in a greenhouse. Dispersal distance and establishment (germination and seedling growth) were not significantly correlated, although in both species, smaller seeds dispersed farther, and showed lower germination and lower seedling growth rates. This apparent paradox can partly be explained by the significant influence of other factors such as release height and environment (wind and vegetation), which explained more variation in dispersal than did terminal velocity. Another potential explanation is the variation in seed traits: germination is strongly positively related to seed mass, weakly positively related to plume loading, but not significantly related to terminal velocity. This weakening of the correlation with germination is due to additional layers of trait (co)variability: for instance, seed mass and pappus size are positively correlated, and thus big seeds partially compensate for the negative effect of seed mass with larger pappi. Our mechanistic approach can thus lead to a better understanding of both potentially opposing selection pressures on traits like seed mass, and diluting effects of other seed, plant and environmental factors.

\section{Introduction}

Seed size is one critical factor affecting several aspects of the plant colonization process. This trait may have either positive or negative effects on two key early steps in colonization, dispersal and establishment, and thus represents a likely trade-off between different colonization stages. In wind-dispersed plants seed size, or more specifically, seed mass, may affect dispersal negatively by increasing the seed settling velocity (Greene and Johnson 1993; Greene and Quesada 2005). Conversely, it has been demonstrated in many plants (not just wind-dispersed species), that seed mass tends to positively affect germination ability and 
seedling growth (Turnbull et al. 1999; Turnbull et al. 2004). Thus, by increasing seed mass, wind dispersed plants may trade dispersal success for germination and establishment success. This has been pointed out repeatedly in studies of dispersal and establishment within and among species (Strykstra et al. 1998; Soons and Heil 2002; Debain et al. 2003; Jakobsson and Eriksson 2003). In some cases the relationships may be different, e.g. for animal-dispersed seeds where seed size and dispersal distance is not necessarily negatively related (Coomes and Grubb 2003), and for secondary wind dispersal where the relationship is unimodal (Schurr et al. 2005). This may change or eliminate the negative correlation. Moreover, even when seed mass has significant and opposing effects on dispersal and establishment, they themselves may not be negatively related (Soons and Heil 2002; Debain et al. 2003). This may be due to low variability in commonly used dispersal proxies such as terminal velocity (Soons and Heil 2002; Debain et al. 2003), in which case a negative correlation will not be detected using a purely empirical approach. Therefore, to understand and resolve this apparent paradox, a mechanistic analysis of the dispersal-establishment relationship with realistic variation affecting dispersal and germination is required. This is an important step towards understanding the implications for evolution of seed size in relation to dispersal and establishment.

In this paper, we start to address this potentially fruitful line of inquiry. Specifically, we test the conditions for the existence of negative dispersal-establishment correlations using empirical studies of dispersal, germination and seedling growth for two Carduus thistles. Using mechanistic statistical models for the dispersal of the two species, coupled with statistical models of germination and establishment, we address the components of the dispersal-establishment relationship to investigate how the overall putative trade-off is affected by species traits and the environment.

\section{Material and methods}

\section{A conceptual model}

Our starting point for this analysis is a conceptual model of how plant traits and environment interact to influence dispersal and establishment (Fig. 1). By "dispersal” we mean the movement of a seed from its mother plant to its destination location. Thus dispersal is only the first step of colonization, which also includes establishment, i.e. germination, survival and plant growth. In this paper we focus on the physical displacement involved in dispersal and on the germination of dispersed seeds and early seedling survival and growth.

In the conceptual model several factors appear as "predictor" and "response" variables for different relationships. We carried out a set of empirical studies of dispersal, germination and seedling growth as dependent on seed traits to test these basic relationships and their effects on dispersal and early establishment for a pair of wind-dispersed thistles, Carduus nutans and C. acanthoides. We focus mostly on the biological links in the empirical studies, while the meteorological relationships between environmental variables (wind at measurement height, vegetation height, release height and wind between release height and ground) were modelled as described below.

\section{The species}

Our study species are two economically important invasive weeds: Carduus nutans L. and C. acanthoides L. (musk and plumeless thistle; Asteraceae). These thistles are originally from Eurasia, but have spread to most other continents (Holm et al. 1979). The life-history and demography of the species is well-known from several studies (Desrochers et al. 1988; Shea and Kelly 1998; Shea et al. 2005; Shea et al. 2006; Jongejans et al. 2007b; Jongejans et al. 2008). Both species are primarily found in pastures and disturbed areas and seem to do particularly well on fertile soils over limestone (Desrochers et al. 1988). They often establish after disturbance (Jongejans et al. 2007b) Both species are short-lived monocarpic perennials, and colonize exclusively by seed. Carduus nutans has on average slightly larger seeds (3.0- 
$4.0 \mathrm{~mm}$ long) than C. acanthoides $(2.5-3.5 \mathrm{~mm})$. Carduus nutans also often grows taller than C. acanthoides and produces more seeds per flower head, but fewer flower heads per plant (Desrochers et al. 1988; Skarpaas and Shea 2007). In Central Pennsylvania, flowering of $C$. nutans is usually completed by late June, and the peak dispersal season is in July; for $C$. acanthoides the peak dispersal season is July-August.

\section{A mechanistic dispersal model}

In natural environments, the dispersal distance of a seed depends on environmental factors in addition to seed mass and derived traits such as settling velocity, and hence the dispersalestablishment relationship may be modified by the environment. Mechanistic models of wind dispersal typically include variables such as seed release height, horizontal wind speed and various aspects of air instability, in addition to terminal velocity (Kuparinen 2006). Many of these models involve complex simulations, but the WALD analytical model of long-distance dispersal has been found to predict dispersal well for a number of wind-dispersed species (Katul et al. 2005), including the Carduus thistles considered here (Skarpaas and Shea 2007). This model is derived from Lagrangian fluid mechanics theory and predicts an inverse Gaussian (Wald) distribution of dispersal distances $r$ (Katul et al. 2005, eqn 5b):

$p(r)=\left(\frac{\lambda}{2 \pi r^{3}}\right)^{\frac{1}{2}} \exp \left(-\frac{\tau(r-\mu)^{2}}{2 \mu^{2} r}\right)$.

The location parameter $\mu$ (the mean) and the scale parameter $\tau$ are related to species and environment characteristics by

$\mu=\frac{H U}{F}$

$\tau=\left(\frac{H}{\sigma}\right)^{2}$,

where $H$ is the seed release height, $F$ is seed settling velocity, $U$ is the hourly mean horizontal wind velocity between $H$ and the ground, and $\sigma$ is a turbulent flow parameter reflecting wind variation due to vegetation structure and weather conditions (Katul et al. 2005). $\sigma$ is derived from the horizontal wind speed under the assumptions that the dissipation rate can be estimated from surface roughness and friction velocity, and that the friction velocity is proportional to the vertical turbulence (see Skarpaas and Shea 2007, Appendix).

According to this model, the expected dispersal distance for a single seed is $\mu$ (the mean of the inverse Gaussian distribution; Evans et al. 2000), which is given by the standard ballistic equation (equation 2). The variance depends on both $\mu$ and $\tau$ (Evans et al. 2000). The probability that a seed reaches a certain distance is given by 1-CDF $(r)$, where $\operatorname{CDF}(r)$ is the cumulative distribution function of the Wald model, i.e. the integral of the probability density function (equation 1). The distribution of dispersal distances of an entire population of seeds (the dispersal kernel) also depends on the variability of the parameters underlying $\mu$ and $\tau$ during the release period. To account for variability in terminal velocity, release height and wind conditions for extended periods of time (more than one hour), the WALD model can be integrated over these variables to obtain the dispersal kernel $k(r)$ (Skarpaas and Shea 2007):

$$
k(r)=\iiint p(H) p(U) p(F) p(r) d H d U d F
$$

where $p(H), p(U)$ and $p(F)$ are the probability densities of $H, U$ and $F$, respectively, and $p(r)$ is the WALD model (equation 3 ). We used this integrated model to estimate distributions of dispersal distances on the basis of independent measurements of environment (wind, vegetation height) and plant traits (seed release height, terminal velocity) in the experiments described below. 


\section{Dispersal experiments}

Eight dispersal experiments were carried out in Central Pennsylvania during the dispersal season (July-October) in 2003 and 2004 (Table 1). Seeds from the dispersal experiments in 2004 were used for seed trait and germination studies (see below). As the experiments involved the release of seeds of invasive species, the experiments were carried out at sites where the species already occurred (Allen and Shea 2006). Seeds were drawn from pools of seeds collected from several plants $(>5)$ in two populations of each species near the study sites. C. nutans seeds were collected in the Elliotsburg area, Perry County, PA; C. acanthoides seeds were collected in the State College area, Centre County, PA. For each species we selected two sites with different vegetation heights corresponding to the natural habitats of the species: one site with low vegetation (pasture) and one with high vegetation (wasteland). Maximum vegetation heights (flowering stalks) were $0.54 \pm 0.25 \mathrm{~m}$ and $1.27 \pm$ $0.49 \mathrm{~m}$ at the low and high vegetation sites respectively (mean \pm SD of measurements at 20 random points at each site). At each site we carried out two dispersal experiments to cover a range of wind speeds (Table 1 ). The experiments were all carried out over a period of 2-4 hours in the late morning or early afternoon on sunny days.

We measured field wind speed and direction using an automated mobile weather station with an anemometer mounted at $2 \mathrm{~m}$ above the ground. In the two experiments carried out in 2003, horizontal wind speeds were measured using a Young cup anemometer. For the six experiments in 2004 we used a 3D ultrasonic anemometer (CSAT3, Campbell Scientific, Utah, USA) to measure wind speeds in three dimensions (including updrafts). Horizontal wind speeds for 2004 were calculated as the vector sum of the two horizontal components. In both years, wind speeds were stored every $10 \mathrm{~s}$ using a CR-10X datalogger (Campbell Scientific). Wind speed and turbulence between the release height and the ground was estimated using the logarithmic wind profile and a mechanistically based turbulence approximation involving horizontal wind speed and standard meteorological parameters (the von Karman and Kolmogorov constants and surface roughness parameters), as described in the appendix of Skarpaas and Shea (2007).

In each experiment we released 40-150 dispersal units (filled achenes with intact pappi) one at a time. The dispersal units were released at random heights in the range 0.30 $2.30 \mathrm{~m}$ (corresponding roughly to flower head heights on the plants), pre-determined by a random number generator. Each dispersal unit was released by hand at the beginning of a 10second recording interval. As soon as the procedure was completed for one dispersal unit, we repeated the whole procedure with the next dispersal unit. We followed each dispersal unit and measured the distance from the release point to the point where it first landed, or, in a few cases, was lost from sight. Although we recorded the last distance at which the lost dispersal units were observed, they were not included in any analyses in this study, because measurements of traits and establishment were carried out on seeds collected from the dispersal experiments.

\section{Seed traits}

The dispersal units from the dispersal field experiments carried out in 2004 were collected and stored individually in vials to preserve the pappi for measurements in the lab. The maximum diameter of the pappus, and the maximum width and length of the achene ('seed' hereafter) were measured using a digital micrometer. Settling velocity (terminal velocity) was measured by dropping each intact dispersal unit through an air-tight tube and timing the descent through $1.16 \mathrm{~m}$ using a stopwatch. To minimize bias from acceleration, the dispersal units were allowed to accelerate for $7 \mathrm{~cm}$. To minimize measurement error, five replicate measurements for each dispersal unit were averaged. Finally, the mass of each seed with the pappus removed was measured using an electronic balance. 


\section{Germination and seedling establishment}

After lab measurements were completed for all seeds, a seed germination trial was conducted between October 20 and November 28, 2004, using all the seeds from dispersal studies 2, 4, 6 and 7 (Table 1): 110 seeds of Carduus nutans; 170 of C. acanthoides; 280 in total. Each seed was randomly assigned a position on one of six trays in the greenhouse. The seeds were planted in bare soil, $0.5 \mathrm{~cm}$ below the surface, which has been shown to be optimal for these species (McCarty et al. 1969). The six trays were placed in a greenhouse with a temperature range of $18-27^{\circ} \mathrm{C}$, artificial light $12 \mathrm{hrs} /$ per day (7:00am-7:00pm) and 30-80\% air humidity. The trays were watered regularly. The planted seeds were checked daily and the date of each germination was recorded, as well as the survival of germinated seedlings. Once a week (from November 7 until November 28, 2004), we recorded the maximum diameter of the rosette and the length of the longest leaf for each seedling.

\section{Analysis}

We tested the relationships among species characteristics (seed mass, pappus diameter, plume loading, release height, settling velocity), environmental variables (vegetation height and wind speeds) and dispersal and establishment (germination and early plant growth) using generalized linear regression models (GLM). In the figures we present results for the four studies where we have data on dispersal, seed traits and establishment (studies 2, 4, 6 and 7 in Table 1), but include additional analyses in the text for the full dispersal data set (all studies in Table 1) where only dispersal-related variables are involved. Settling velocity $F$ has been found to be linearly related to the square root of plume loading $L$ (Andersen 1993; Meyer and Carlson 2001):

$F=\alpha \sqrt{L}$.

$\alpha$ is a constant and the plume loading $L$ is given by (Greene and Johnson 1990):

$L=\frac{M}{A}$,

where $M$ is seed mass (mg) and $A$ is pappus area $\left(\mathrm{mm}^{2}\right)$ assuming a circular plume (Matlack 1987). On a logarithmic scale, dispersal distance, seed settling velocity and seed mass should be linearly related (eqs. 2, 5 and 6). Thus, in the statistical analysis these variables were log transformed. Plume loading was square root transformed when used as a predictor for settling velocity (eq. 5). For the WALD model parameters we obtained independent estimates (not fitted to dispersal distances). The relationship between germination and seed mass were analyzed using logistic regression. All analyses were carried out in R (R Development Core Team 2009).

\section{Results}

Large (heavy) seeds had bigger pappi in both species (Fig. 2A; linear regression, $\mathrm{P}<0.001$ ). However, an increase in pappus area was not sufficient to compensate for the increased mass of the seed: plume loading increased linearly with seed mass in both species (Fig. 2B; linear regression, $\mathrm{P}<0.001$ ). Carduus nutans had significantly heavier seeds (Table 2), larger pappi than C. acanthoides (Fig. 2A, linear regression, $\mathrm{P}<0.001$ ), but lower plume loadings (Fig. $2 \mathrm{~B}$, linear regression, $\mathrm{P}<0.001)$. Terminal velocity, the main dispersal trait of the achenepappus unit, increased linearly with the square root of plume loading in both species (Fig. 2C; linear regression, $\mathrm{P}<0.001)$. Terminal velocity was lower in $C$. nutans, but not significantly so (Table 2).

Dispersal distances were strongly affected by plant traits and environmental factors, but there was no significant difference between the species (Fig 3; linear regression, $\mathrm{P}>$ 0.195). Seeds with higher terminal velocities dispersed shorter distances (Fig. 3A; linear regression, $\mathrm{P}<0.001$ ). Seed release height (plant height), on the other hand, affected dispersal distances positively (Fig. 3B; linear regression, $\mathrm{P}<0.001$ ). This was also true for the full 
dispersal data set including all 8 experiments listed in Table 1 (linear regression, $\mathrm{P}<0.001$ ). As expected, dispersal distances also increased with the ambient wind speed (Fig 3C, linear regression, $\mathrm{P}<0.001$; full dispersal data set: $\mathrm{P}<0.001)$. Of the factors that explained a significant proportion of the variation in dispersal distance (ANOVA, $\mathrm{P}<0.05$; for the seeds where all measurements were available) wind speed explained the most (45\%), followed by terminal velocity (16\%), vegetation height (7\%) and seed release height (2\%).

The wind speed experienced by each individual dispersal unit varied considerably between dispersal experiments in high and low vegetation (see also Marchetto et al. 2010b). The resulting distributions of dispersal distances were significantly skewed towards shorter distances in high vegetation for both species (Fig. 4; Kolmogorov-Smirnov one-sided tests, $\mathrm{P}$ $<0.001)$. The WALD model predicted the dispersal distance distributions extremely well for Carduus nutans in low vegetation, where there was no significant difference among the observed and predicted distributions (Kolmogorov-Smirnov two-sided test, $\mathrm{P}=0.653$ ). In the three other cases the model predictions deviated slightly from the observations at intermediate distances (Kolmogorov-Smirnov two-sided tests, $\mathrm{P}<0.034$ ), but the model nevertheless predicted the distributions well in both low and high vegetation considering that predictions were made on the basis of independent measurements of the predictors.

While seed mass affected dispersal negatively (Fig 5A), it affected establishment positively. The probability of germination increased significantly with seed mass (Fig. 5B; logistic regression, $\mathrm{P}<0.001)$. Of the 110 Carduus nutans seeds 15 germinated $(13.6 \%)$, while 25 of the $170 \mathrm{C}$. acanthoides seeds germinated (14.7\%). There was no significant difference between the species in germination (logistic regression, $\mathrm{P}=0.164$ ). Although some large seeds germinated earlier than small seeds, seed mass did not significantly affect germination time in any of the species (linear regression, $\mathrm{P}>0.100$ ). Nor did it affect seedling survival; all seedlings survived until the end of the experiment. However, seed mass did affect early seedling growth in both species positively, both in terms of leaf growth (Fig. 5C) and rosette growth (data not shown, but similar pattern as leaf growth; linear regression, $\mathrm{P}<$ 0.001). By both growth measures, $C$. acanthoides seedlings grew significantly faster than $C$. nutans seedlings for comparable seed masses (Fig. 5C; linear regression, $\mathrm{P}<0.001$ ).

Despite the fact that seed mass affected dispersal negatively and establishment positively, there was no statistically significant negative relationship between dispersal and establishment in our data. The probability of germination was predicted well by seed mass (see above), but increasingly worse by plume loading (logistic regression coefficient $\mathrm{c}=$ $0.138, \mathrm{P}=0.058)$, terminal velocity $(\mathrm{c}=3.07, \mathrm{P}=0.215)$ and dispersal distance $(\log r ; \mathrm{c}=-$ 0.041, $\mathrm{P}=0.739$; Fig. 6A). Controlling for wind speed $(\log U)$ and release height $(\log H)$ made the relationship between dispersal and germination stronger but still not statistically significant (logistic regression coefficient $\mathrm{c}=-0.236, \mathrm{P}=0.191$ ). Similarly, seedling leaf and rosette growth were not significantly related to the observed dispersal distance (linear regression coefficients 0.016 and 0.004 respectively; $\mathrm{P}=0.851$ and 0.933 ; Fig. $6 \mathrm{~B}$ and $\mathrm{C}$ ).

Even though dispersal distance and germination were not significantly negatively related, there may still be opposing selection pressures on seed mass since seed mass affected dispersal distance negatively and establishment positively. Under the assumption that these separate and opposing effects could cause a negative correlation between the ability to arrive and the ability to establish in a new location, we explored the predicted optimal seed mass in either species (Fig. 7). Note that this hypothetical picture assumes that there is no interaction effect of seed mass and vegetation height on the probability of establishment (i.e. that small and large seeds are affected similarly by vegetation height). The predicted seed mass, where effects on dispersal and germination are optimally balanced, is strongly modified by environmental conditions. For example, the optimal seed mass for colonizing safe sites more than $2 \mathrm{~m}$ away from the mother plant is drastically reduced by high vegetation, which 
effectively lowers the wind speed experienced by the seed. The reduction in the optimal seed mass is stronger for $C$. acanthoides than for $C$. nutans under comparable conditions.

\section{Discussion}

4 In a direct comparison of dispersal and germination we found no statistical support for a time our results suggest evolutionarily relevant opposing effects of seed mass on dispersal and establishment for both Carduus nutans and C. acanthoides. This has also been demonstrated for many other species (Strykstra et al. 1998; Soons and Heil 2002; Debain et al. 2003; Jakobsson and Eriksson 2003). This apparent paradox, which has also been observed in some other studies (e.g. Soons and Heil 2002; Debain et al. 2003), can be explained by low variability in commonly used dispersal proxies such as terminal velocity. Our study also raises other likely explanations. One possible explanation is the significant influence of other factors such as release height and environment (wind and vegetation) on dispersal. In our study these factors explained more of the variability in dispersal distance than did terminal velocity. Similarly, strong effects of the environment were reported by Nathan et al. (2002) who found that relatively heavy seeds were uplifted above the canopy (i.e. likely to be longdistance dispersed). Another possible explanation for the lack of a clear negative relationship between dispersal and establishment is the variation in seed traits and their measurement: germination is strongly positively related to seed mass, less clearly but still positively related to plume loading, but not significantly related to terminal velocity and dispersal distance. This dilution of effects of seed traits on germination is partly because additional layers of variability in traits and measurements reduce our ability to see a relationship with a limited sample size, and partly because of trait co-variability. For instance, seed mass is positively correlated with pappus size. As pointed out by e.g. Sakai et al. (1998), heavy seeds are not poor colonizers if the weight is compensated for by bigger dispersal structures such as wings or plumes. For the Carduus thistles tested here, heavier seeds had larger pappi, but not sufficiently large to compensate for the increase in plume loading and terminal velocity.

In our analyses, all the relationships in the pathways from seed mass to dispersal and to establishment are statistically significant and the seed mass-mediated effects are sufficiently large to cause more than five-fold differences in the probability of dispersal beyond the mean dispersal distance (approximately $2 \mathrm{~m}$ ) and in the probability of germination (Fig. 7). This suggests that there is a mechanistic basis for a negative dispersal-establishment relationship for both Carduus species; the best dispersers may not be the best colonizers, even though the direct correlation between dispersal and establishment appears to be overwhelmed by variability in environmental factors in the particular context of our studies. In more constant environments (predictable winds, small range of release heights, etc.), seed massmediated effects will likely be relatively more important.

The mechanisms involved, and the shape of the dispersal-establishment relationship, seem to be somewhat different in the two species. C. acanthoides had higher terminal velocities than $C$. nutans for any given seed mass. This is mostly due to higher plume loadings in C. acanthoides, but other factors, such as lower plume density may also affect terminal velocity (Greene and Johnson 1990; Marchetto et al. 2010a). Regardless of the underlying cause, the predicted optimal seed mass for colonization was larger for $C$. nutans than for C. acanthoides in similar environments (Fig. 7). Interestingly, observed seed mass is even smaller than predicted by our models for both species in low vegetation and for $C$. nutans in high vegetation, which suggests that the ruderal existence and long-distance dispersal may be very important for these species.

The environment strongly influenced the dispersal-establishment relationship for both species in our study. As expected, wind had a strong positive effect on dispersal distances. Vegetation height reduces wind speed at dispersal height, and thereby reduces dispersal 
distances. Seeds were also sometimes intercepted by vegetation in the high-vegetation experiments (low outliers in Fig 3). For both species the loss of dispersal capacity is dramatic in high vegetation / low wind, which in turn affects the hypothesized optimal seed mass for colonization (Fig 7). This general conclusion can be (and has been) drawn on the basis of seed characteristics only (terminal velocity and germination), as the expected dispersal distance in the common ballistic equation (equation 2; also the mean of the WALD model) is inversely related to terminal velocity. However, estimating the exact shape of the relationship under varying environmental conditions requires a probability distribution of dispersal distances, provided by the mechanistic dispersal model (WALD) in this study. Using this model we can estimate the shape of the dispersal-establishment relationship for any of the seed traits and environmental variables included in the model.

This being said, one must keep in mind that any model is a simplification of nature. This goes for the WALD model as well as for the conceptual model (Fig. 1) in this study. Although the WALD model has proved to be a good model for several species at the scales at which we can measure (Katul et al. 2005; Skarpaas and Shea 2007), it may not be able to represent extreme long-distance dispersal (Katul et al. 2005). This will affect our ability to represent the dispersal-establishment relationship correctly if suitable habitat and safe sites are far apart. In nature, there are also additional possible connections among the variables that we ignore in our analysis because of the experimental design. For instance, in our dispersal experiments seeds were released at random with respect to wind speeds, but natural seed release is strongly affected by wind, humidity and other environmental conditions (Skarpaas et al. 2006; Jongejans et al. 2007a). Moreover, vegetation height and seed release height (a function of plant height) are probably positively correlated in many natural settings (except for e.g. pastures in which cattle graze around thistles), but in our experiments seeds were released at random heights independently of vegetation height. Finally, vegetation structure, including vegetation height, will also most likely affect germination and seedling survival and growth through its effect on light and water availability. In our experiments, germination and seedling growth tests were carried out under standardized favourable conditions in a greenhouse. This allows the direct analysis of the dispersal-establishment relationship on the same seeds, while also increasing the statistical power in comparison to realistic conditions (where a worst-case scenario would be no germination at all). This means that our exploration of consequences for the dispersal-establishment relationship does not include effects of vegetation on germination and seedling growth. There is some evidence that establishment and seedling growth are reduced in dense and tall vegetation, suggesting better recruitment in open microsites (Jongejans et al. 2007; Shea unpublished data), but we do not know how this relates to seed size. If tall vegetation reduces germination in all seeds, the optimum in Figure 7 would be the same, but if small seeds are affected disproportionately (see e.g. Coomes and Grubb 2003), the optimum seed mass would be higher.

The evolutionary outcome in any particular case may deviate from the relationship depicted in Figure 7 for a variety of reasons. Even if there is a negative correlation between dispersal and establishment, this is not sufficient to imply causality or the existence of a tradeoff (Knops et al. 2007). We did not control for genetic effects (and have no information about seed masses of parents), so here we are dealing with correlations of phenotypic traits for which the genetic basis is unknown. As far as we know, the heritability of seed size in Carduus has not been investigated, but studies of a range of other plant species suggest that seed size may be affected by parental genes as well as parental environments (e.g. Stratton 1989; Mazer and Wolfe 1992; Wheelwright 1993). Furthermore, the seed mass predictions in this study are made on the level of individual seeds and not on the level of mother plants: the fitness of mother plants, i.e. the relative number of expected offspring over a lifetime, also depends on other trade-offs such as growth vs. reproduction (Metcalf et al. 2008) and seed 
number vs. seed size (Jakobsson and Eriksson 2003), in addition to environmental factors such as post-dispersal seed predation (Jongejans et al. in prep.) and the availability of safe sites (Geritz et al. 1984; Bullock et al. 1995; Bullock 2000). The panels in Figure 7 apply within homogeneous patches of high or low vegetation. Widely dispersed seeds may encounter different conditions for establishment: if they are better than in the source patch (e.g. less competitive), any negative dispersal-establishment relationship may be cancelled out; if they are worse, it may be even stronger. Moreover, the dispersal-establishment correlation may also be modified by processes at later stages in the life cycle: for instance, the disadvantage of $C$. acanthoides in the initial colonization by seed (dispersal and germination) may be countered by faster seedling growth (Fig 5C).

Thus a number of factors, both species-specific and environmental in origin, will introduce variability that will affect the evolutionary outcome in any particular case. Simplifications are necessary to separate the essence from the noise, and a mechanistic modelling approach has the potential to include, and integrate over, relevant sources of variability. A complete mechanistic analysis of all of the relevant factors is beyond the scope of this paper, but we consider this a useful first step. A mechanistic approach will help to understand the seed mass-dispersal-establishment paradox, and also to study more complex relationships than just positive, negative or non-existent correlations between dispersal and establishment. This makes it possible to go beyond simple detection and description of the dispersal-establishment relationship and has allowed us to explore its mechanistic dependence on species traits and environmental conditions in detail. Such a mechanistic approach will lead to a better understanding and quantification of potentially opposing selection pressures on traits like seed mass, as well as of the diluting effects of other seed, plant and environmental factors.

\section{Acknowledgements}

We are grateful to Jeff Buterbaugh, Paul Chen, Matt Clark, Wilmer Garman, Brian Jones, Pete LeVan, Melanie Northrup, Emily Leichtman, Emily Rauschert, Christina Saylor, Zeynep Sezen and Laura Warg for assistance in field and lab studies, and to two anonymous reviewers for valuable comments. This work was funded by the National Science Foundation (grant no. DEB-0315860 and DEB-0614065 to KS), the Norwegian Research Council (grant no. 161484/V10 to OS) and the Netherlands Organization for Scientific Research (NWO veni-grant 863.08.006 to EJ).

\section{References}

Allen MR, Shea K (2006) Spatial segregation of congeneric invaders in central Pennsylvania, USA. Biological Invasions 8:509-521

Andersen M (1993) Diaspore morphology and seed dispersal in several wind-dispersed Asteraceae. American Journal of Botany 80:487-492

Bullock JM (2000) Gaps and seedling colonization. In: Fenner MJ (ed) Seeds: the ecology of regeneration in plant communities, 2 edn. CAB International, Wallingford, pp 375-395

Bullock JM, Hill BC, Silvertown J, Sutton M (1995) Gap colonization as a source of grassland community change: Effects of gap size and grazing on the rate and mode of colonization by different species. Oikos 72:273-282

Coomes DA, Grubb PJ (2003) Colonization, tolerance, competition and seed-size variation within functional groups. Trends in Ecology \& Evolution 18:283-291

Debain S, Curt T, Lepart J (2003) Seed mass, seed dispersal capacity, and seedling performance in a Pinus sylvestris population. Ecoscience 10:168-175

Desrochers AM, Bain JF, Warwick SI (1988) The biology of Canadian weeds. 89. Carduus nutans L. and Carduus acanthoides L. Canadian Journal of Plant Science 68:10531068

Evans M, Hastings N, Peacock B (2000) Statistical distributions. Wiley, New York 
Geritz SAH, de Jong TJ, Klinkhamer PGL (1984) The efficacy of dispersal in relation to safe site area and seed production. Oecologia 62:219-221

Greene DF, Johnson EA (1990) The aerodynamics of plumed seeds. Functional Ecology 4:117-125

Greene DF, Johnson EA (1993) Seed mass and dispersal capacity in wind-dispersed diaspores. Oikos 67:69-74

Greene DF, Quesada M (2005) Seed size, dispersal, and aerodynamic constraints within the Bombacaceae. Am. J. Bot. 92:998-1005

Holm L, Pancho JV, Herberger JP, Plucknett DL (1979) A geographical atlas of world weeds. John Wiley and Sons, New York

Jakobsson A, Eriksson O (2003) Trade-offs between dispersal and competitive ability: a comparative study of wind-dispersed Asteraceae forbs. Evoltuionary Ecology 17:233246

Jongejans E, Pedatella N, Shea K, Skarpaas O, Auhl R (2007a) Seed release by invasive thistles: the impact of plant and environmental factors. Proceedings of the Royal Society B: Biological Sciences 274:2457-2464

Jongejans E, Shea K, Skarpaas O, Kelly D, Sheppard AW, Woodburn TL (2008) Dispersal and demography contributions to population spread of Carduus nutans in its native and invaded ranges. Journal of Ecology 96:687-697

Jongejans E, Skarpaas O, Tipping PW, Shea K (2007b) Establishment and spread of founding populations of an invasive thistle: the role of competition and seed limitation. Biological Invasions 9:317-325

Katul GG et al. (2005) Mechanistic analytical models for long-distance seed dispersal by wind. The American Naturalist 166:368-381

Kuparinen A (2006) Mechanistic models for wind dispersal. Trends in Plant Science 11:297301

Marchetto KM, Jongejans E, Jennis ML, Haner EM, Sullivan CT, Shea K (2010a) Shipment and storage effects on the terminal velocity of seeds. Ecological Research 25:83-92

Marchetto KM, Jongejans E, Shea K, Isard SA (2010b) Patch characteristics affect projected invasion speed. Oikos in press

Matlack GR (1987) Diaspore size, shape and fall behavior in wind-dispersed plant species. American Journal of Botany 74:1150-1160

Mazer SJ, Wolfe LM (1992) Planting density influences the expression of genetic variation in seed mass in wild radish (Raphanus sativus L.: Brassicaceae). American Journal of Botany 79:1185-1193

McCarty MK, Scifres CJ, Smith AL, Horst GL (1969) Germination and early seedling development of musk and plumeless thistles. In: Research Bulletin. College of Agriculture and Home Economics, University of Nebraska, pp 1-28

Metcalf CJE, Rees M, Buckley YM, Sheppard AW (2008) Seed predators and the evolutionary stable flowering strategy in the invasive plant, Carduus nutans. Evolutionary Ecology

Meyer SE, Carlson SL (2001) Achene mass variation in Ericameria nauseosus (Asteraceae) in relation to dispersal ability and seedling fitness. Functional Ecology 15:274-281

Nathan R et al. (2002) Mechanisms of long-distance dispersal of seeds by wind. Nature 418:409-413

R Development Core Team (2009) R: A language and environment for statistical computing. In, 2.9.0 edn. R Foundation for Statistical Computing, Vienna, Austria

Sakai S, Kikuzawa K, Umeki K (1998) Evolutionarily stable resource allocation for production of wind-dispersed seeds. Evolutionary Ecology 12:477-485 
Schurr FM, Bond WJ, Midgley GF, Higgins SI (2005) A mechanistic model for secondary seed dispersal by wind and its experimental validation. Journal of Ecology 93:10171028

Shea K, Kelly D (1998) Estimating biocontrol agent impact with matrix models: Carduus nutans in New Zealand. Ecological Applications 8:824-832

Shea K, Kelly D, Sheppard AW, Woodburn TL (2005) Context-dependent biological control of an invasive thistle. Ecology 86:3174-3181

Shea K, Sheppard A, Woodburn T (2006) Seasonal life history models for the integrated management of the invasive weed nodding thistle (Carduus nutans) in Australia. Journal of Applied Ecology 43:517-526

Skarpaas O, Auhl R, Shea K (2006) Environmental variability and the initiation of dispersal: turbulence strongly increases seed release. Proceedings of the Royal Society of London - Series B 273:751-756

Skarpaas O, Shea K (2007) Dispersal patterns, dispersal mechanisms and invasion wave speeds for invasive thistles. The American Naturalist 170:421-430

Soons MB, Heil G (2002) Reduced colonization capacity in fragmented populations of winddispersed grassland forbs. Journal of Ecology 90:1033-1043

Stratton DA (1989) Competition prolongs expression of maternal effects in seedlings of Erigeron annuus (Asteraceae). American Journal of Botany 76:1646-1653

Strykstra RJ, Pegtel DM, Bergsma A (1998) Dispersal distance and achene quality of the rare anemochorous species Arnica montana L.: implications for conservation. Acta Botanica Neerlandica 47:45-56

Turnbull LA, Coomes D, Hector A, Rees M (2004) Seed mass and the competition/colonization trade-off: competitive interactions and spatial patterns in a guild of annual plants. Journal of Ecology 92:97-109

Turnbull LA, Rees M, Crawley MJ (1999) Seed mass and the competition/colonization tradeoff: A sowing experiment. Journal of Ecology 87:899-912

Wheelwright NT (1993) Fruit size in a tropical tree species: variation, preference by birds, and heritability. Plant Ecology 107-108:163-174 


\section{Figures}

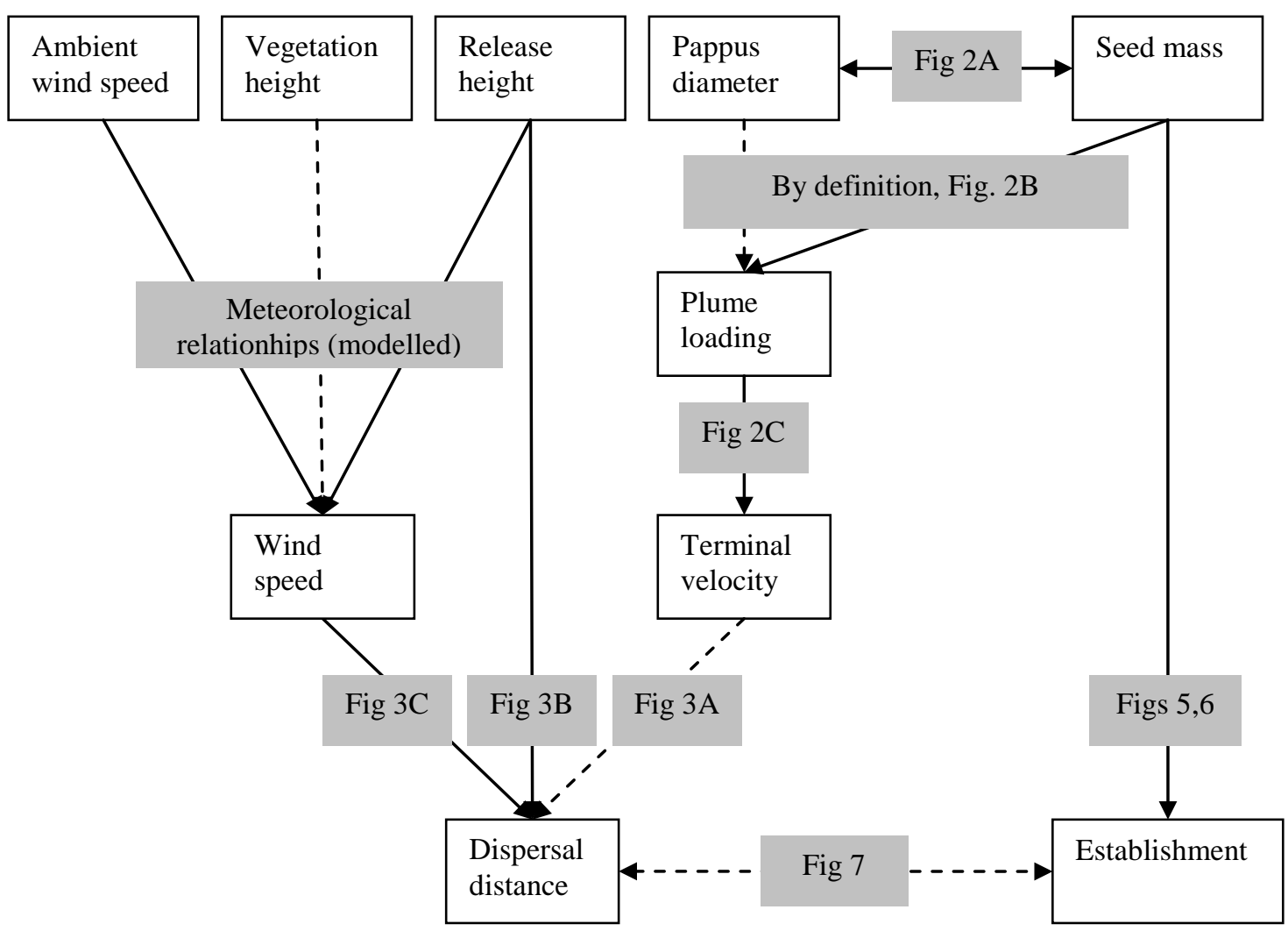

Figure 1. Conceptual model of modeled and hypothetical relationships among plant traits, environment, dispersal and establishment. Solid lines indicate positive relationships; dashed lines indicate negative relationships. Gray boxes refer to figures illustrating results for each connection, except for the meteorological relationships, which are not tested in this study, but modelled using standard methods (see Methods). 'Ambient wind speed' is the horizontal wind speed at measurement height $(2 \mathrm{~m})$; 'Wind speed' is the wind speed as perceived by the dispersal unit, estimated as the average horizontal wind speed between release height and the ground. As measures of 'Establishment' we use germination or seedling growth, as specified for each analysis. 

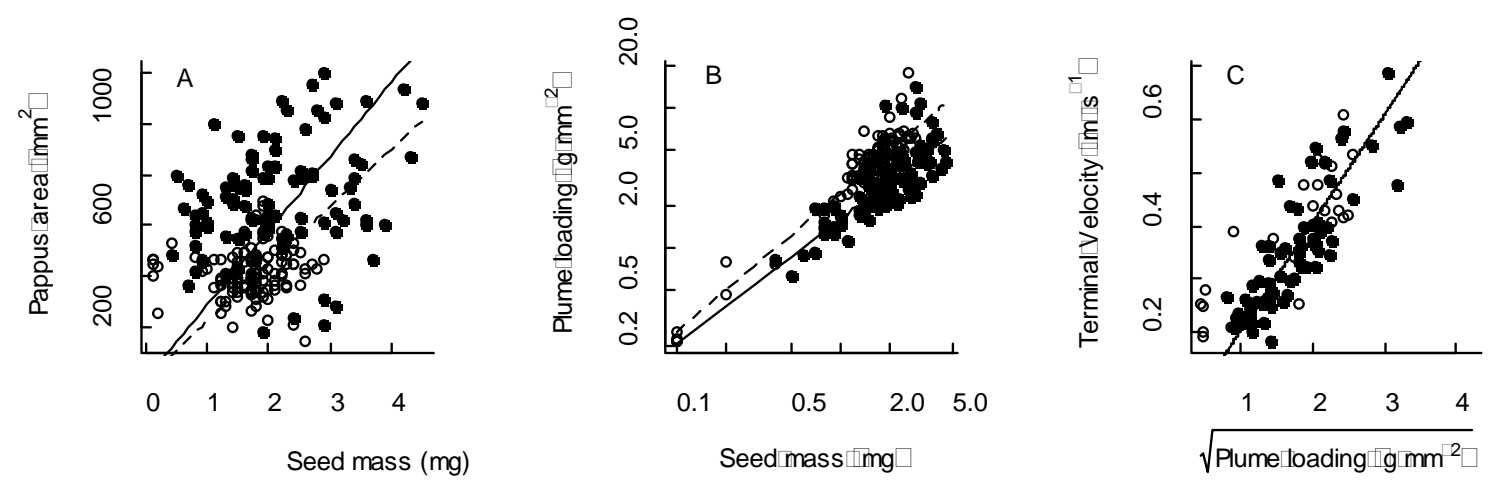

Figure 2. Relationships among dispersal-related seed traits in Carduus. Observations and fitted regression models for Carduus nutans (filled circles; solid lines) and C. acanthoides (open circles; dashed lines). In $C$ the single regression line applies to both species; they were not significantly different. $\mathrm{R}^{2}$ values: (A) 0.83, (B) 0.96, (C) 0.96 .
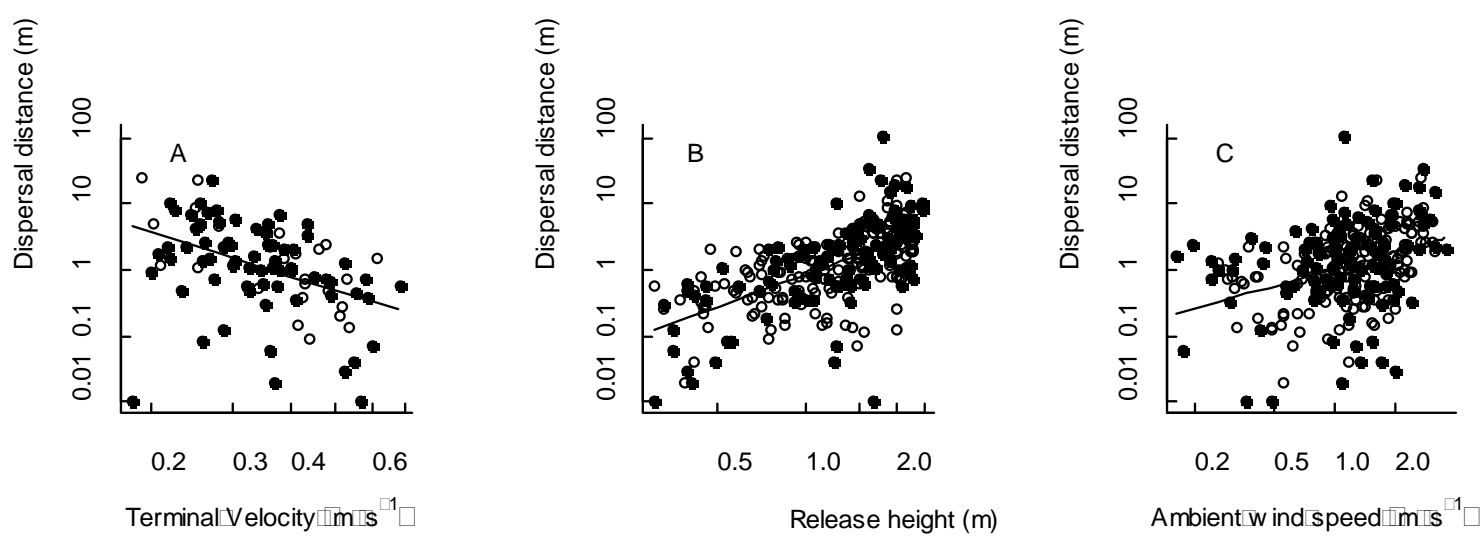

Figure 3. Relationships among Carduus seed traits, environmental conditions and dispersal. 10 Observations for Carduus nutans (filled circles) and C. acanthoides (open circles) and regression models for both species (lines). $\mathrm{R}^{2}$ values: (A) 0.18 , (B) 0.38 , (C) 0.13 . 


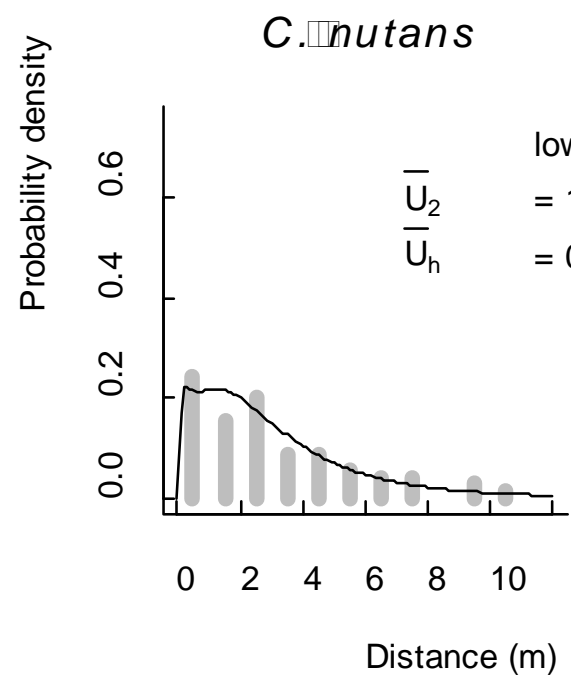

C. acanthoides
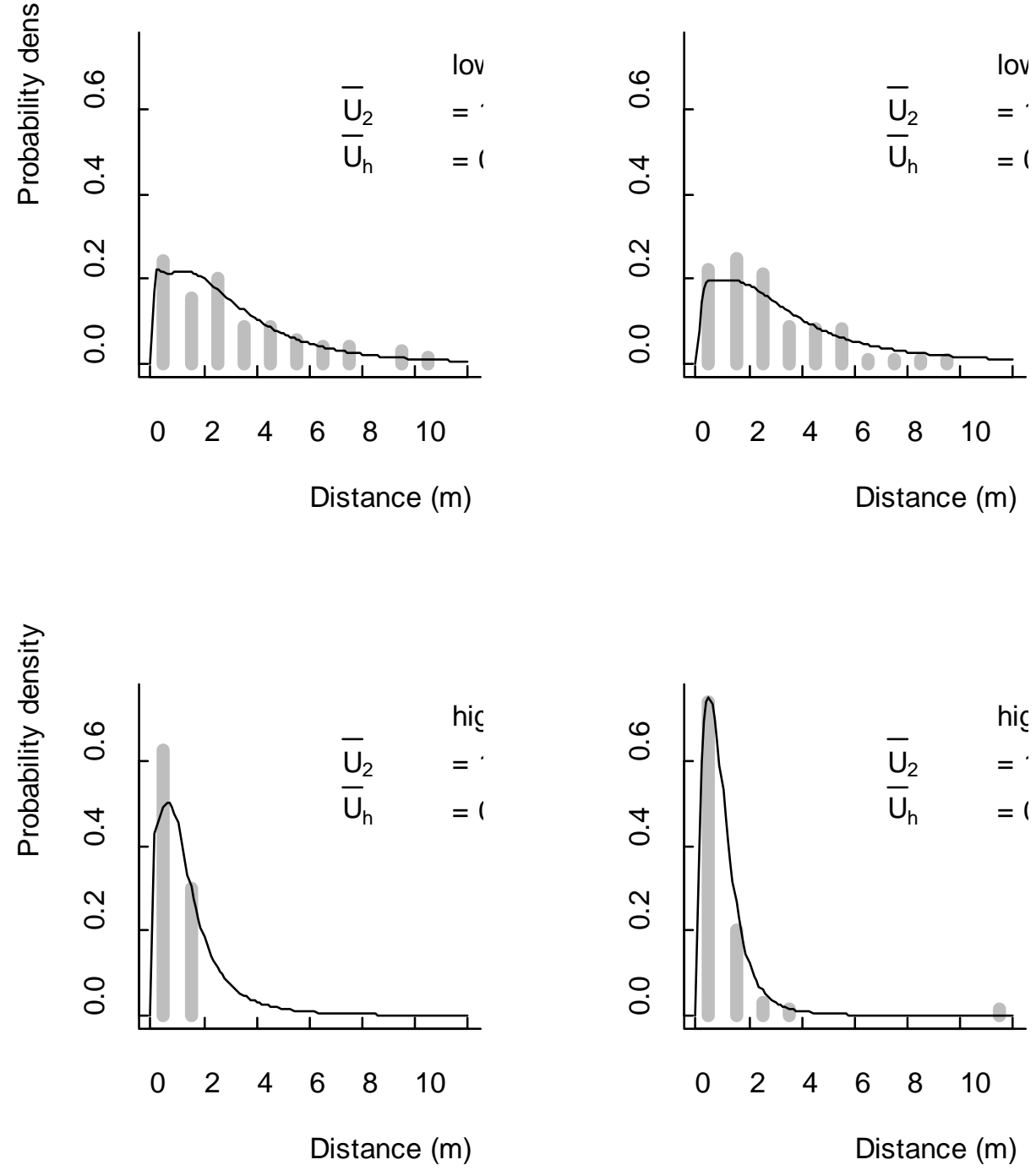

2 Figure 4. Observed (bars) and predicted distributions of dispersal distances using the 3 integrated WALD model (lines) for Carduus nutans and C. acanthoides in low and high 4 vegetation (a few observations $>12 \mathrm{~m}$ are omitted for clarity; see Fig. 3). Mean wind speeds 5 are given for each study at measurement height $\left(2 \mathrm{~m} ; \mathrm{U}_{2}\right)$ and between release height and 6 ground $\left(\mathrm{U}_{\mathrm{h}}\right)$. 

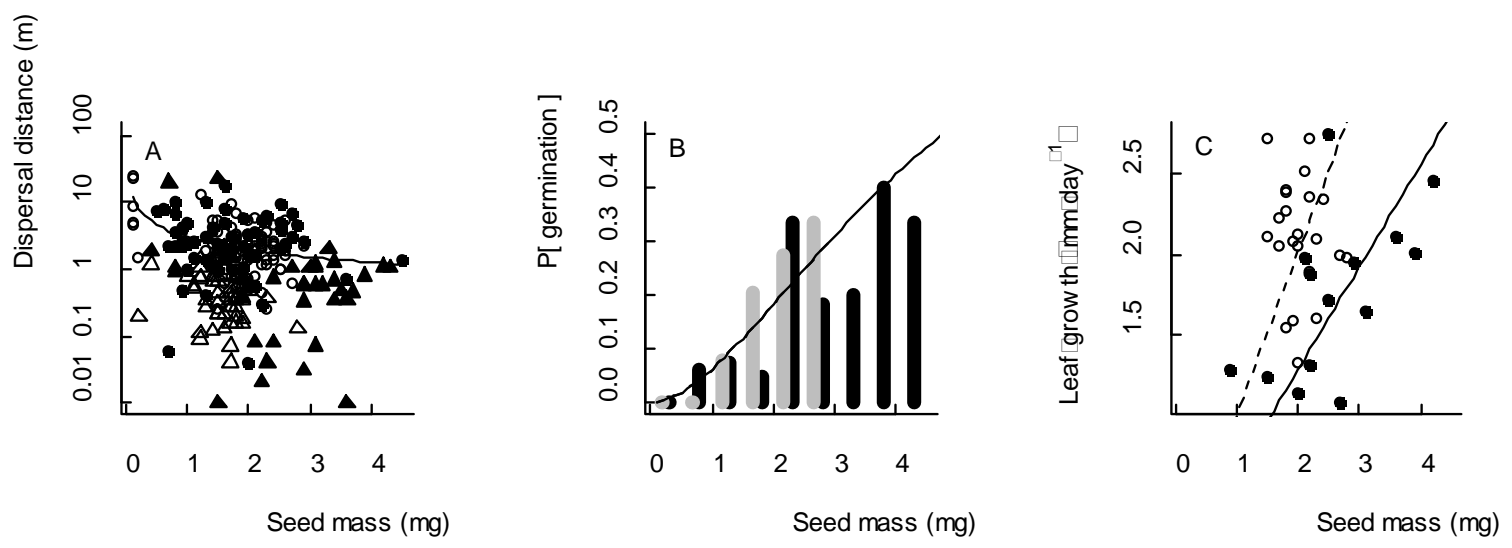

Figure 5. Effects of seed mass on (A) dispersal, (B) germination and (C) leaf growth in Carduus nutans (filled symbols) and C. acanthoides (open symbols). In A, observations from low-vegetation studies are indicated by circles and high-vegetation studies by triangles. B shows the observed (bars) and predicted (line) probability of germination as a function of seed mass (logistic regression) for $C$. nutans (black bars) and C. acanthoides (gray bars). C shows observed and predicted seedling growth as a function of seed mass (linear regression through the origin), measured as the average daily growth of the longest leaf (left) for $C$. nutans (filled circles, solid lines) and C. acanthoides (open circles, dashed lines).

11
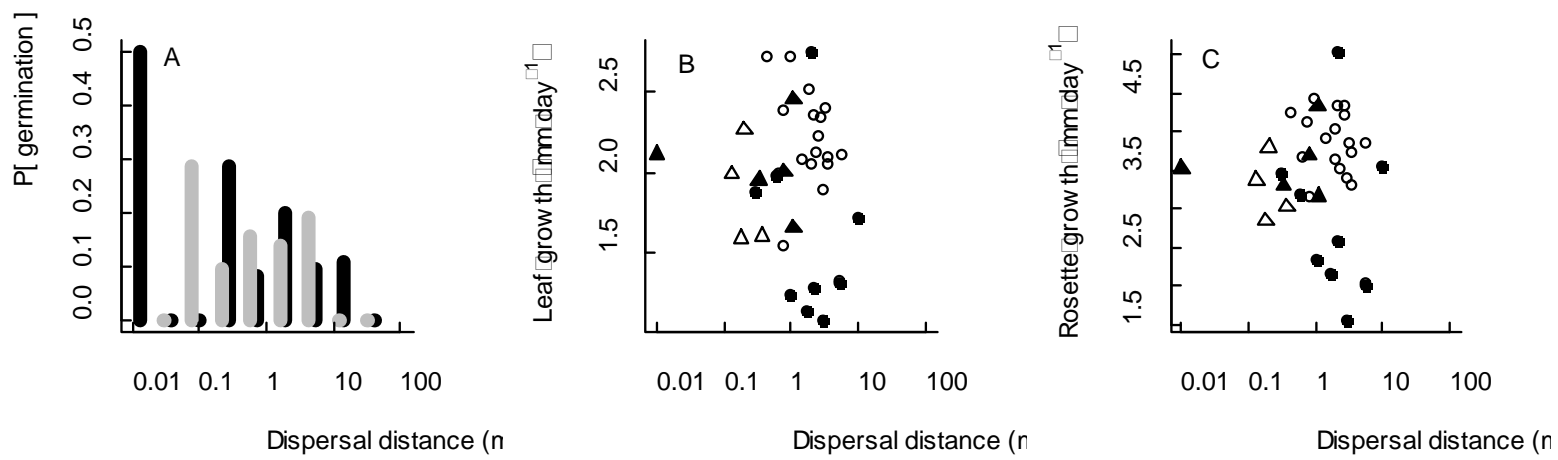

Figure 6. Relationships between observed dispersal and (A) germination, (B) leaf growth and (C) rosette growth in Carduus nutans (filled symbols, black bars) and C. acanthoides (open symbols, gray bars). In B and C observations from low-vegetation studies are indicated by circles and high-vegetation studies by triangles. 

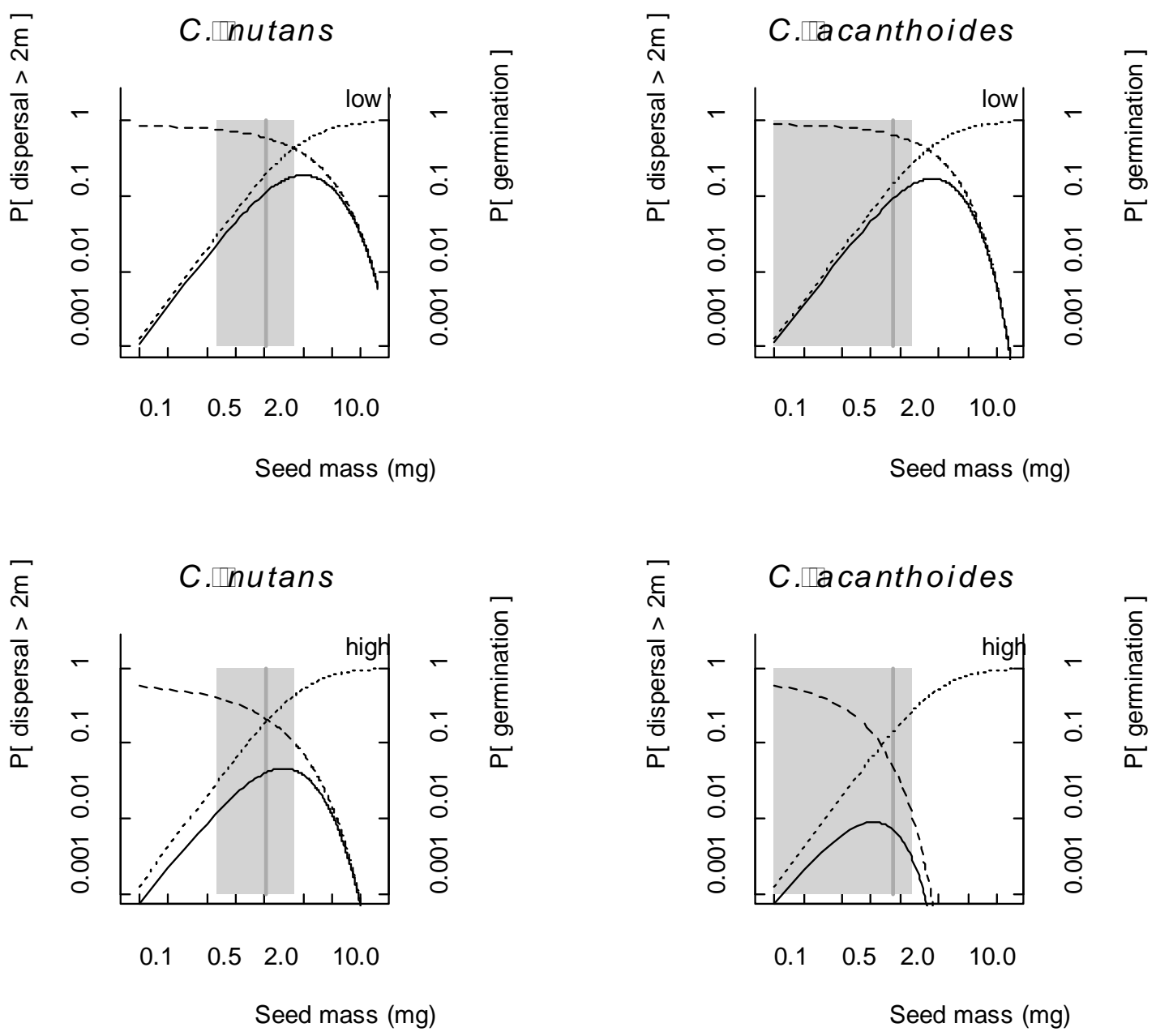

Figure 7. Modelled relationship between dispersal and establishment (germination and seedling survival), and the effect of the environment, assuming homogeneous effects of vegetation height on establishment across seeds of all sizes. Each panel shows the probability of dispersing $>2 \mathrm{~m}$ (dashed line, predicted by the WALD model; Equation 1), the probability of establishment (dotted line, predicted by the logistic regression model; Fig 5) and the resulting probability of colonization $>2 \mathrm{~m}$ from the mother plant (solid line; product of dispersal and establishment probabilities) as a function of seed mass. Means (gray vertical 9 line) and ranges (95\% confidence intervals; gray shading) of observed seed mass are indicated 10 in each case. Note that the evolutionary optimal seed mass may also depend on several other 11 factors (see the text for details). 
Table 1. Dispersal experiments for Carduus nutans and C. acanthoides at sites with low and high vegetation (pastures and wastelands respectively) in Central Pennsylvania 2003 and 2004. Number of seeds released $(N)$ and horizontal $\left(U_{z}\right)$ and vertical $(W)$ wind speeds $(m e a n s$, SD in parentheses) at $2 \mathrm{~m}$ above ground. Seeds from experiment 2, 4, 6 and 7 were used for seed trait and germination trials.

$\begin{array}{lllllrll} & \text { Date } & \text { Site } & \text { Species } & \text { Vegetation } & N & U_{2}\left(\mathrm{~ms}^{-1}\right) & W_{2}\left(\mathrm{~ms}^{-1}\right) \\ 1 & \text { 29 July 2003 } & \text { Garman farm, Elliotsburg } & \text { C. } \text { nutans } & \text { low } & 150 & 1.00(0.69) & -* \\ 2 & \text { 23 July 2004 } & \text { Garman farm, Elliotsburg } & \text { C. } \text { nutans } & \text { low } & 70 & 1.33(0.72) & 0.01(0.10) \\ 3 & \text { 1 Sep. } 2004 & \text { Allen \& Commerce, Carlisle } & \text { C. } \text { nutans } & \text { high } & 70 & 1.07(0.51) & -0.10(0.13) \\ 4 & \text { 22 Sep. 2004 } & \text { Allen \& Commerce, Carlisle } & \text { C. } \text { nutans } & \text { high } & 40 & 0.97(0.50) & -0.10(0.20) \\ 5 & \text { 16 Sep. 2003 } & \text { Haller farm, State College } & \text { C. acanthoides } & \text { low } & 150 & 2.99(0.83) & -* \\ 6 & \text { 17 Aug. 2004 } & \text { Haller farm, State College } & \text { C. acanthoides } & \text { low } & 100 & 1.66(0.67) & -0.10(0.12) \\ 7 & \text { 17 Aug. 2004 } & \text { Big Hollow, State College } & \text { C. acanthoides } & \text { high } & 70 & 1.03(0.56) & -0.08(0.20) \\ 8 & \text { 4 Oct. } 2004 & \text { Big Hollow, State College } & \text { C. acanthoides } & \text { high } & 54 & 1.21(0.68) & -0.07(0.30)\end{array}$

* Vertical wind speeds were not measured in 2003.

Table 2. Traits of the achene-pappus dispersal unit (mean and SD) for Carduus nutans and C. acanthoides, with sample sizes ( $N$ ) and $P$-values for a two-sided t-test for the difference between them.

Trait

Seed mass (mg)

Plume diameter (mm)

Plume area $\left(\mathrm{mm}^{2}\right)$

Plume loading $\left(\mathrm{g} \mathrm{mm}^{-2}\right)$

Terminal velocity $\left(\mathrm{m} \mathrm{s}^{-1}\right)$

\begin{tabular}{rrrrr} 
C. nutans & \multicolumn{2}{c}{ C. acanthoides } \\
Mean (SD) & $N$ & Mean (SD) & $N$ & $P$ \\
$2.1(1.0)$ & 96 & $1.7(0.6)$ & 142 & 0.001 \\
$29.6(4.7)$ & 107 & $22.9(2.7)$ & 163 & $<0.001$ \\
$706.9(212.2)$ & 107 & $419.3(96.5)$ & 163 & $<0.001$ \\
$3.26(2.27)$ & 96 & $4.27(1.95)$ & 139 & $<0.001$ \\
$0.35(0.11)$ & 68 & $0.39(0.12)$ & 25 & 0.184
\end{tabular}

